\title{
Mechanical characterisation of novel polyethylene nanocomposites by nanoindentation
}

\author{
A. S. Alghamdi ${ }^{1}$, I. A. Ashcroft ${ }^{1} \&$ M. Song ${ }^{2}$ \\ ${ }^{I}$ Mechanical, Materials \& Manufacturing Engineering, \\ University of Nottingham, UK \\ ${ }^{2}$ Department of Materials, Loughborough University, UK
}

\begin{abstract}
Ultra-high Molecular Weight Polyethylene (UHMWPE) is a high performance polymer which is currently used in lightweight body armour and total joint replacement applications because of its high toughness and wear resistance, respectively. However, the high molecular weight also makes processing difficult and expensive, which has led to research to find alternative materials with similar performance but better processability. The aim of this work is to investigate the mechanical properties of novel polyethylene nanocomposites by means of nanoindentation. The localized mechanical properties were used to evaluate the dispersion of the nanoparticle into the polymer matrix. Scratch, creep and wear resistance of the polyethylene nanocomposites were also studied. Nanoindentation tests provided information about the dispersion quality of the nanoparticles, which can be used to develop processing methods. The addition of the nanoparticles was found to improve the scratch, creep and wear resistance of the polyethylene.
\end{abstract}

Keywords: polyethylene, nanocomposite, carbon nanotube, nanoclay, nanoindentation, scratch, wear.

\section{Introduction}

Ultra-high molecular weight polyethylene (UHMWPE) is a high performance thermoplastic with outstanding mechanical properties, such as high wear strength, chemical resistance and high toughness, which provide not only practical benefits but also scientific interest [1-3]. However, its extremely high 
molecular weight, and subsequent high viscosity, raises difficulties in processing using standard techniques, such as twin screw extrusion and compression moulding. Reducing the viscosity of UHMWPE is an effective method of avoiding these processing difficulties. Blending UHMWPE with other polymers that have lower viscosity, such as high density polyethylene (HDPE), can therefore be used to improve processability. HDPE has a similar structure to UHMWPE but with lower molecular chain length, however, it exhibits lower wear resistance, yield strength and toughness than UHMWPE [1]. This reduction in performance on adding HDPE to UHMWPE can potentially be mitigated, whilst retaining the improved processability, by the addition of nanoreinforcement, which has been shown to improve the mechanical performance of polyethylene [4-11].

Depth sensing indentation (DSI) is an advanced technique, which is capable of providing valuable information about the near-surface properties of solid polymers, such as indentation elastic modulus, indentation hardness, elasticplastic, viscoelastic (creep) and viscoplastic behaviour [12]. Recently, this technique has become increasingly popular in the investigation of the nearsurface properties of polymer nanocomposites and their correlation to the nanoparticle loading [13-15]. The effects of nanoparticles on the scratch and wear resistance of polymer nanocomposites have also been studied at micro-level $[14,15]$. To date, no work has been carried out to evaluate the dispersion of the nanoparticles, the creep behaviour, or the scratch and wear resistance of polyethylene nanocomposites by means of DSI. Therefore, in this paper, the dispersion of carbon nanotube (CNT) and inorganic nanoclay in a UHMWPE/HDPE blend matrix using two different mixing methods was evaluated by DSI. The effects of the nanoparticle addition on the creep behaviour, scratch and wear resistance were also investigated.

\section{Experimental methods}

\subsection{Materials}

The materials tested in this study were UHMWPE/HDPE blended polymers with CNT and nanoclay fillers. Nascent UHMWPE powders (Sabic ${ }^{\mathbb{}}$ UHMWPE3548) were purchased from SABIC [16] which had an average molecular weight of $3 \times 10^{6} \mathrm{~mol} / \mathrm{g}$. HDPE powders (ExxonMobil ${ }^{\mathrm{TM}}$ HDPE HMA014) were purchased from ICO Ltd [17]. Natural hectorite nanoclay was supplied by Elementis specialties [18]. Multi-wall Nanotubes (MWNT) with diameters in the range of $5 \mathrm{~nm}$ to $50 \mathrm{~nm}$, were provided by Nanocyl [19]. Butylated hydroxytoluene and Tris(nonylphenyl) phosphate, supplied by Sigma-Aldrich [20], were used as primary and secondary antioxidants, to maintain the long term thermal stability and melt processing stability, respectively. 


\subsection{Processing}

An in-house pre-mix technology was used to incorporate the CNT or inorganic nanoclay into the UHMWPE and HDPE powders. A twin-screw extruder was used to blend the 75wt.\% UHMWPE and 25wt.\% HDPE powders pre-mixed with CNT or nanoclay, to form nano-filled UHMWPE/HDPE blends with low volume fraction (0.5 wt.\%). Two processing methods (M1 and M2) were used and the mixing temperature was controlled using five zones from feeding port to die, the processing parameters are shown in table 1. A blend of $75 \mathrm{wt} . \%$ UHMWPE and 25wt.\% HDPE, abbreviated to U75H25, was used as the hybrid PE matrix to accommodate the nanofillers. Compression moulding was used to mould the nanocomposite materials. The raw material was placed into a square mould (100 X $100 \times 1.65 \mathrm{~mm})$, and then heated to $190^{\circ} \mathrm{C}$, which is higher than the melting point of the composite (approximately $135^{\circ} \mathrm{C}$ ). Various mould pressures $(154,232,309$, and $386 \mathrm{MPa})$ were investigated to optimise the properties of the material such as hardness and crystallinity. Various holding times at maximum pressure (10,15 and 30 minutes) were also used to identify the most appropriate moulding parameters. The optimal moulding pressure and holding time were found to be $309 \mathrm{MPa}$ and 15 minutes respectively, which resulted in the highest measured values of hardness and crystallinity. After compression moulding, the mould was cooled to room temperature using water.

Table 1: $\quad$ Processing method parameters.

\begin{tabular}{|c|c|c|c|c|c|c|c|}
\hline \multirow{2}{*}{$\begin{array}{c}\text { Processing } \\
\text { Method }\end{array}$} & \multirow{2}{*}{$\begin{array}{c}\text { Extruder } \\
\text { Speed } \\
\text { (rpm) }\end{array}$} & \multicolumn{6}{|c|}{ Processing Temperature $\left({ }^{\circ} \mathrm{C}\right)$} \\
\hline & & Zone 1 & Zone 2 & Zone 3 & Zone 4 & Die & Cooling \\
\hline M1 & 400 & 180 & 190 & 200 & 210 & 220 & water \\
\hline M2 & 190 & 220 & 250 & 260 & 270 & 280 & water \\
\hline
\end{tabular}

\subsection{Material testing and characterisation}

Depth sensing indentation (DSI) experiments were performed on $10 \times 10 \mathrm{x}$ $1.65 \mathrm{~mm}$ specimens at a controlled machine chamber temperature of $24.8 \pm 0.6^{\circ} \mathrm{C}$ using a NanoTest 600 from Micro Materials Ltd (Wrexham, UK). A Berkovich indenter, with face angle of $65.3^{\circ}$, was used to make a grid of $10 \times 10$ indents using $40 \mathrm{mN}$ maximum load, 600s dwell period and $2 \mathrm{mN} / \mathrm{s}$ loading and unloading rates. The results were analysed using the Oliver and Pharr method [21], and then plotted using Matlab software from MathWorks (Cambridge, UK). In this method, the initial portion of the unloading curve is described by the power low relation:

$$
\mathrm{P}=\alpha\left(\mathrm{h}-\mathrm{h}_{\mathrm{r}}\right)^{\mathrm{m}}
$$

where $\mathrm{P}$ is the load, $\alpha$ and $\mathrm{m}$ are constants determined by curve fitting, $\mathrm{h}$ is penetration depth and $h_{r}$ is the depth of the residual impression. The contact stiffness $(\mathrm{S})$ can be obtained by:

$$
S=\frac{d P}{d h}\left(h=h_{\max }\right)=m \propto\left(h_{\max }-h_{r}\right)^{m-1}
$$


The contact depth $\left(\mathrm{h}_{\mathrm{c}}\right)$ at maximum load $\left(\mathrm{P}_{\max }\right)$ can be estimated using:

$$
h_{c}=h_{\max }-\varepsilon \frac{\mathrm{P}_{\max }}{\mathrm{S}}
$$

where $\varepsilon$ is a constant related to the geometry of indenter, which is 0.75 for the Berkovich indenter, $\mathrm{h}_{\max }$ is the maximum penetration depth. Thus, the projected contact area $\left(A_{c}\right)$ is determined from $\left(h_{c}\right)$ by the following relation:

$$
\mathrm{A}_{\mathrm{c}} \approx 24.5 \mathrm{~h}_{\mathrm{c}}{ }^{2}
$$

and hence the indentation hardness $(\mathrm{H})$ is:

$$
H=\frac{P_{\max }}{A_{c}}=\frac{P_{\max }}{24.5 h_{c}^{2}}
$$

For the materials used in this study, a bulge or (nose) effect was found during the initial portion of unloading as a result of creep, which can lead to errors in the calculation of contact depth and contact stiffness. Therefore, a dwell time of 600s was introduced at maximum load to minimize the effect of viscoelastic behaviour. In this study, the Oliver and Pharr method was used to compare the mechanical resistance of the blends and nanocomposites under identical testing conditions.

Micro-scratch and wear tests were also performed on $10 \times 10 \times 1.65 \mathrm{~mm}$ specimens at $24.8 \pm 0.6^{\circ} \mathrm{C}$ using the NanoTest 600 .A diamond probe of $\sim 200 \mu \mathrm{m}$ tip radius (Rockwell) was used to perform single and multi-pass scratches (wear) over tracks of 150 and $100 \mu \mathrm{m}$, respectively. The single scratch procedure involved scans at $15 \mu \mathrm{m} / \mathrm{s}$ velocity, $25 \mathrm{mN}$ load, $2.97 \mathrm{mN} / \mathrm{s}$ loading rate and $100 \mu \mathrm{m}$ distance between scratches. The wear experiments were performed using a multi-pass scratch (11 scratches) technique at $10 \mu \mathrm{m} / \mathrm{s}$ velocity, $25 \mathrm{mN}$ load, $2.97 \mathrm{mN} / \mathrm{s}$ loading rate and $100 \mu \mathrm{m}$ distance between scratches. An initial topography $(0.2 \mathrm{mN}$ constant load) scan was applied before starting each experiment to check the sample preparation. Five repeat tests were performed on each sample and the average result was used in data analysis.

The nanoparticle dispersion was also investigated using a Philips XL30 ESEM-FEG, Scanning Electron Microscope (SEM) from FEI (Eindhoven, The Netherlands). AJEOL 2000FX Transmission Electron Microscope (TEM) from JEOL Ltd. (Welwyn Garden, UK) was used to analyse the dispersion of nanoclay in the blend matrix.

\section{Results and discussion}

\subsection{Dispersion of nanoparticles}

Nanoparticle dispersion is a very important factor in the manufacture of nanocomposites that can affect the mechanical and rheological properties of the composite. It is difficult to achieve a uniform dispersion of nanoparticles in a polymer matrix and in this work two processing methods (M1 and M2) were used in an attempt to minimize the effects of CNT aggregation and to form exfoliated nanoclay platelets. 
The scanning electron microscope (SEM) and the transmission electron microscope (TEM) were used to analyse nanoparticle dispersion in the U75H25 matrix at the micro-scale, as shown in fig. 1. It can be seen that CNT, which is indicated by black arrows in fig 1a is well dispersed in the matrix. Also, the nanoclay layers are dispersed in the blend matrix. The dark region in fig. $1 \mathrm{~b}$ is a separate nanoclay layer. However, enlarging the measurement scale can also provide information about nanoparticle dispersion, which is not achievable using the previous techniques. Therefore, in this work a DSI method was used to investigate near-surface properties of the nanocomposites, in this case indentation hardness, over an area of approximately $1 \mathrm{~mm}^{2}$. The variations in hardness value were used to evaluate the effect of the processing method on the blend morphology and the dispersion of the CNT and inorganic nanoclay. The results are shown in figs. 2 and 3 for processing methods M1 and M2 respectively. In fig. 2, the influence of adding HDPE to the UHMWPE can be seen to significantly increase the indentation hardness and the variation of hardness across the sample, which indicates poor mixing of the two polymer phases (UHMWPE and HDPE). In fig. 3, it can be seen that the hardness of the blend is similar to that of the UHMWPE and there is less variation in hardness than seen with M1. This indicates a better blending of the HDPE into the UHMWPE microstructure.

The addition of very low volume fractions of CNT and nanoclay (0.5 wt.\%) to the blend shows a slight increase in hardness using M1, as seen in fig. 2. However, the variation in hardness by the addition of $0.5 \mathrm{wt} . \%$ CNT indicates the formation of some aggregations of nanoparticles. In fig. 3, the CNT and nanoclay were uniformly dispersed throughout the U75H25 matrix. However, at very low volume fraction of $\mathrm{CNT}$, hardness was increased significantly, which indicates a strong influence of the CNT addition on the near surface properties of $\mathrm{U} 75 \mathrm{H} 25$.
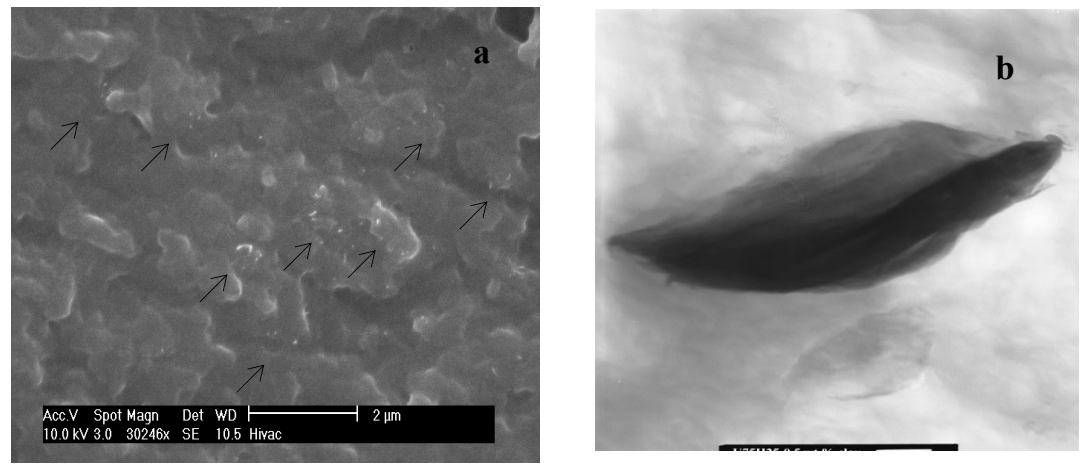

Figure 1: Dispersion of nanoparticle in the U75H25 matrix: a) SEM image for the dispersion of CNT and b) TEM image for the dispersion of nanoclay. 


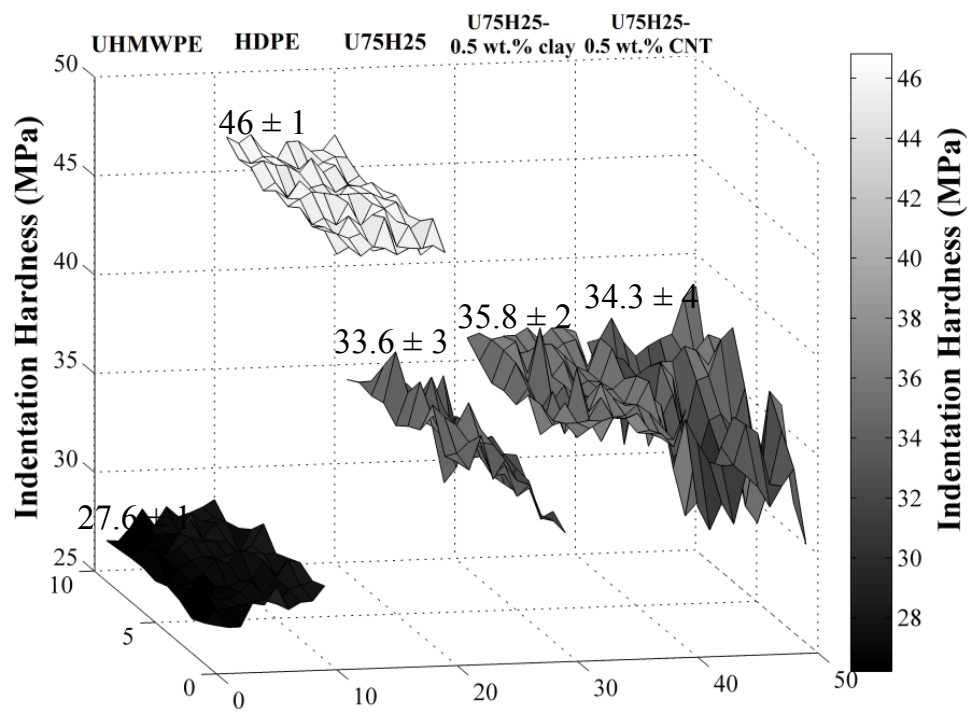

Figure 2: Indentation hardness for polyethylene blend and nanocomposites using processing method M1, including mean and standard deviation values.

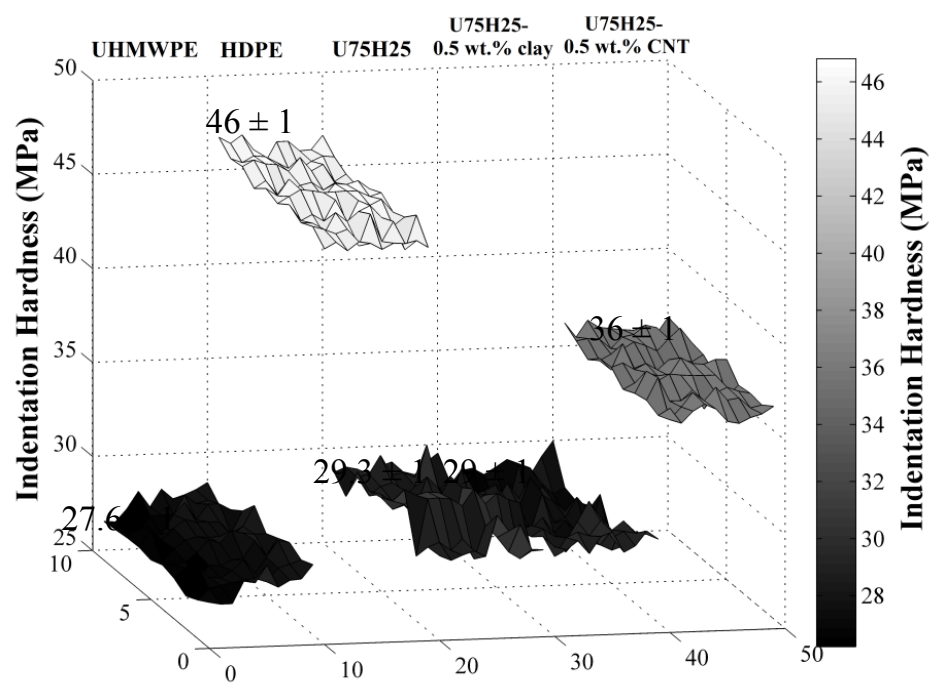

Figure 3: Indentation hardness for polyethylene blend and nanocomposites using processing method M2, including mean and standard deviation values. 


\subsection{Depth sensing indentation results}

Depth sensing indentation (or nanoindentation) can be used to investigate the near-surface mechanical properties of materials. This technique is useful and directly applicable for elastic-plastic materials. Polymers, however, can exhibit time dependent behaviour which affects the initial portion of unloading, and consequently the contact depth and stiffness. Creep on unloading can increase indentation depth resulting in a higher or even a negative slope, which affects the calculated modulus value. Fig. 4 shows the load-displacement curves of UHMWPE, U75H25 and the two nanocomposites. A 600s holding time at the maximum load $(40 \mathrm{mN})$ was used to minimise the effect of creep on unloading. It can be seen that the addition of HDPE to the UHMWPE increases its stiffness. Further increases in stiffness are seen by the addition of the CNT and nanoclay fillers to the blend.

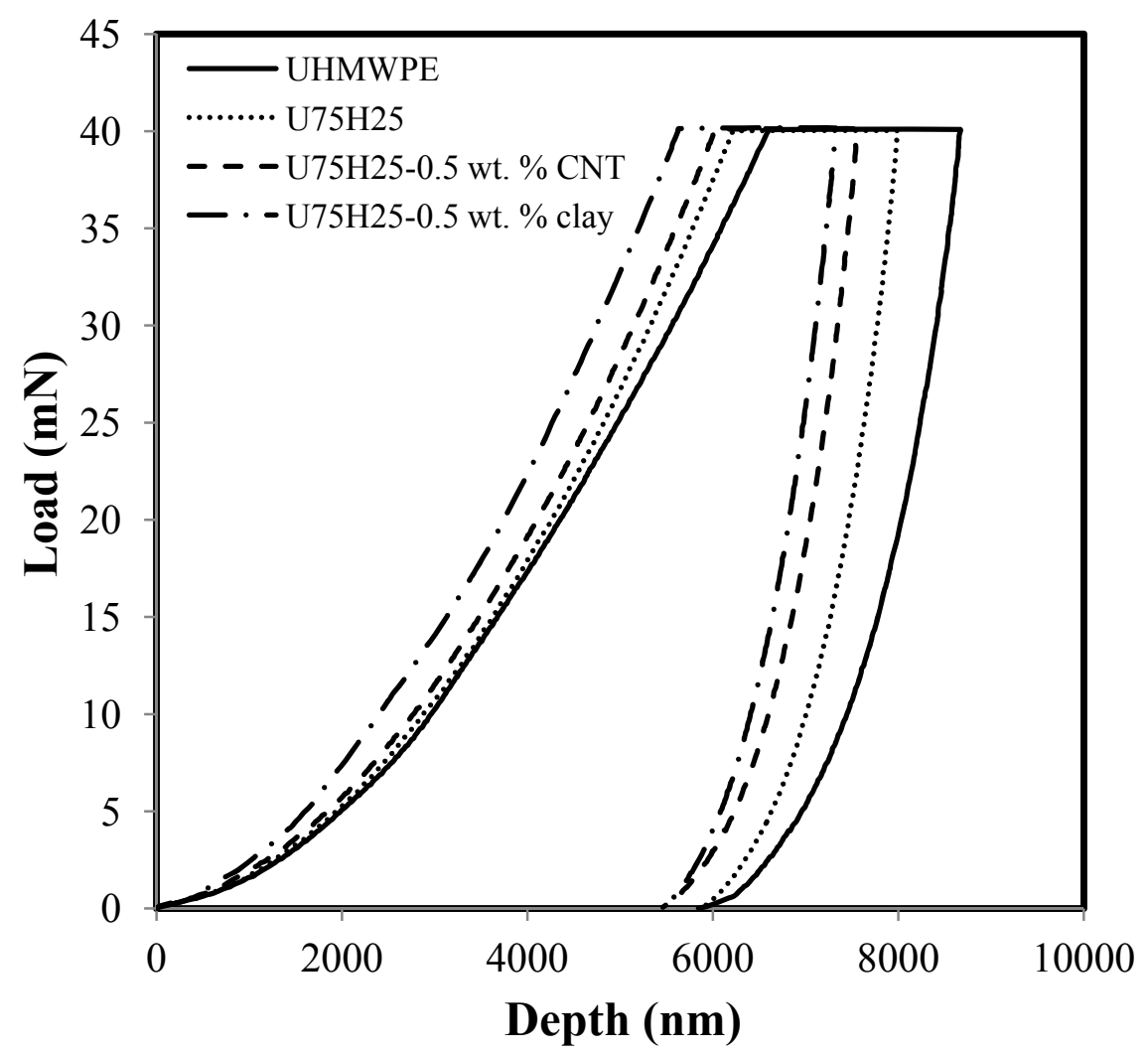

Figure 4: Comparison of the effect of nanoparticle on the nanoindentation behaviour. 


\subsection{Nanoindentation creep results}

Fig. 5 shows the effect of CNT and nanoclay fillers on the creep behaviour of U75H25 and compares them with UHMWPE. It can be seen that the addition of 25 wt.\% HDPE increases the creep resistance of UHMWPE. A further increase in creep resistance can be realised by the addition of CNT or nanoclay. The presence of CNT and nanoclay platelets can inhibit the creep deformation of the blend chains, when subjected to indentation pressure. This also indicate a good load transfer between the blend matrix and the nanoparticles. The improvement in the creep resistance for the nanocomposite materials can also be attributed to the large aspect ratio of the nanoparticle and the interfacial area between nanoparticle and $\mathrm{U} 75 \mathrm{H} 25$ matrix, which enhance load transfer and restrict the mobility of the chains.

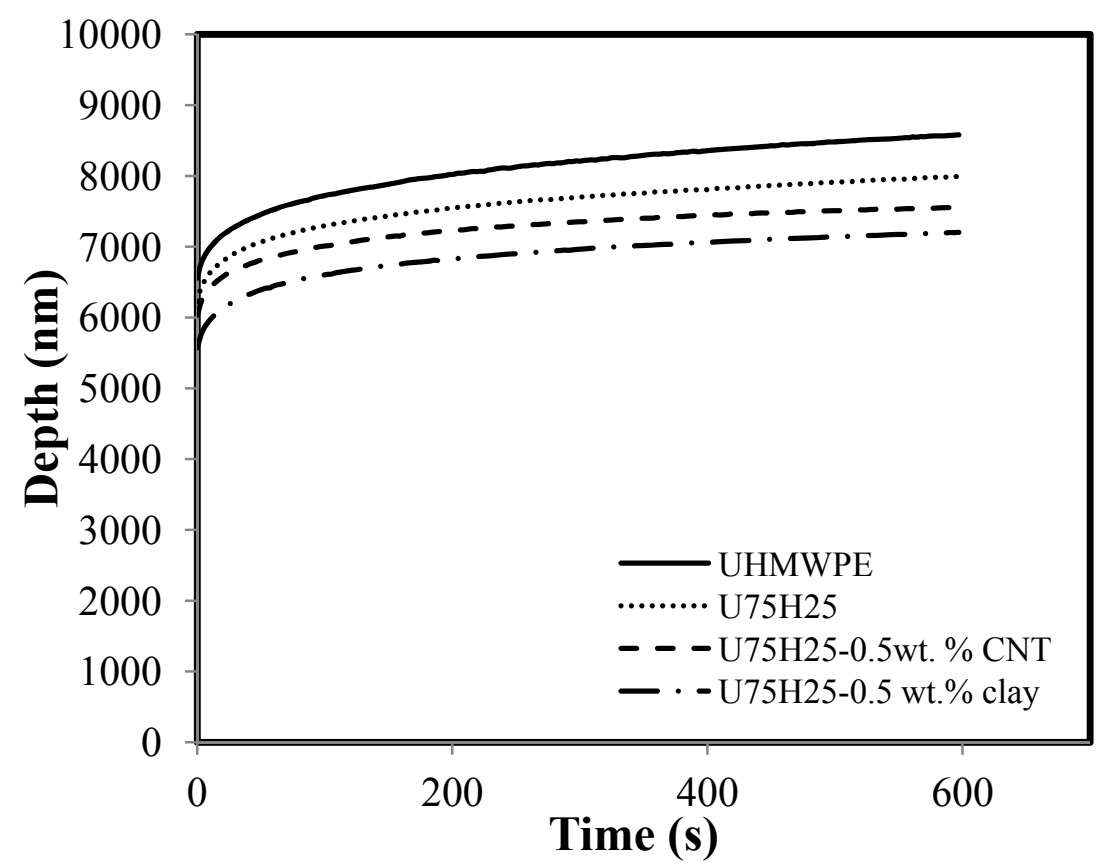

Figure 5: Effect of nanoparticle on the creep resistance of the polyethylene blend.

\subsection{Scratch and wear resistance}

Typical scratch depth profiles from the single and multi-pass scratch tests can be seen in figs 6 and 7, respectively. It is clear that the addition of $0.5 \mathrm{wt} \% \%$ 
nanoclay significantly increases the scratch resistance of the blend material. This can be seen from the reduction in the scratch depth over the scan distance. The addition of CNT shows a slight improvement in the scratch resistance at higher load. The addition of nanoclay induces better wear resistance, which can be evaluated from the plastic depth after 11 scratches, as shown in fig. 7. It can be seen that the scratch and wear resistance are closely related, the nanocomposite with higher scratch resistance also showing improvement in the wear resistance. Different factors can affect the performance of nanocomposites conducted to scratch or wear tests. These include the dispersion (the aspect ratio), the interfacial area, the interaction bonding between nanoparticle and polymer matrix and the exfoliation or intercalation in case of nanoclay platelets.

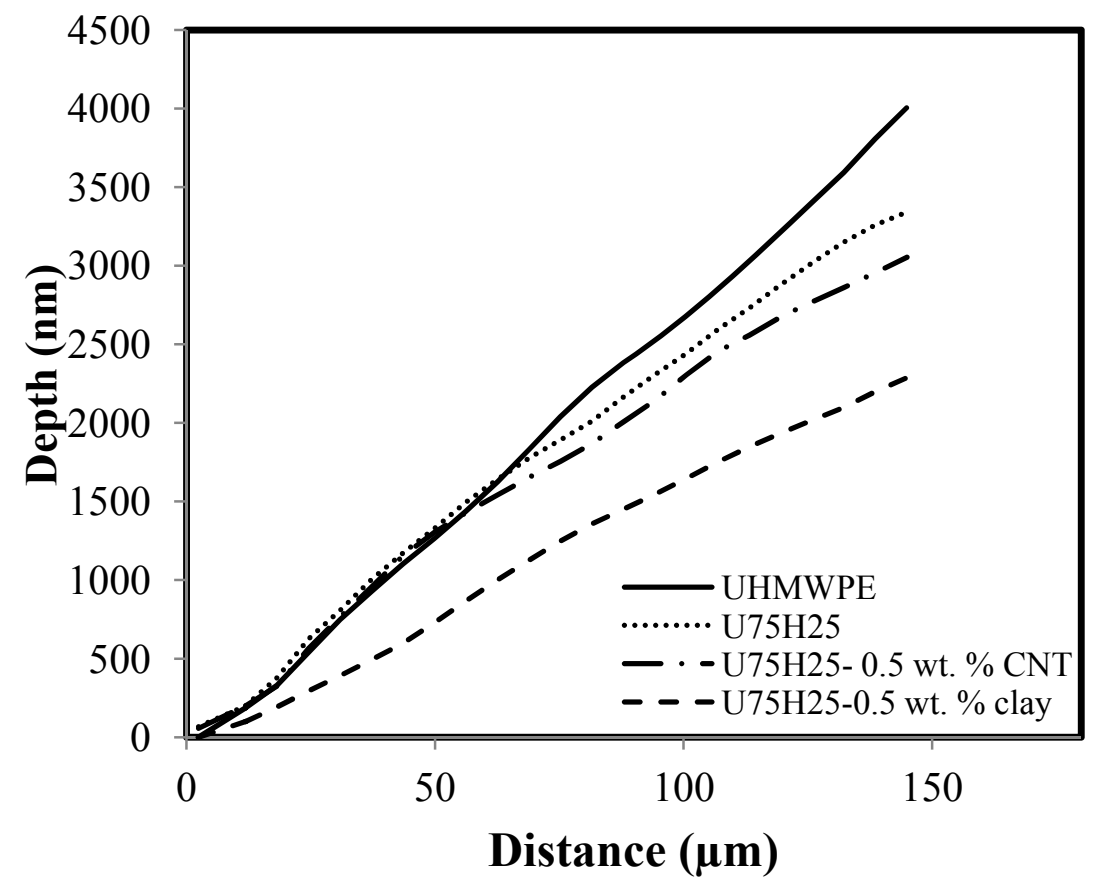

Figure 6: $\quad$ Scratch depth profiles for UHMWPE, blend and nanocomposites at $15 \mu \mathrm{m} / \mathrm{s}$ scan velocity. 


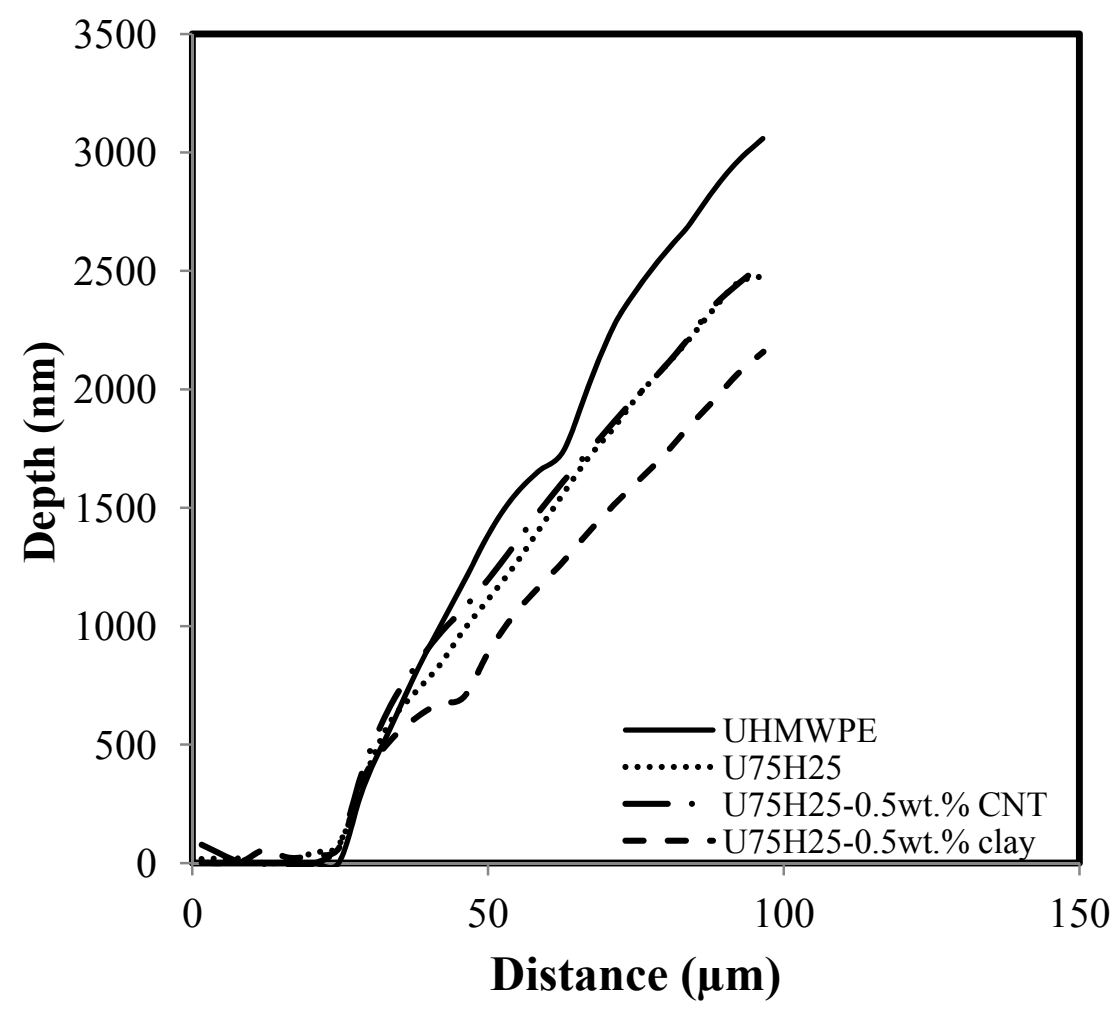

Figure 7: Wear depth profile for UHMWPE, blend and nanocomposites at $10 \mu \mathrm{m} / \mathrm{s}$ scan velocity.

\section{Conclusions}

In this work, the near surface mechanical properties of UHMWPE, U75H25 and nanocomposites with CNT and nanoclay were investigated by nanoindentation. Indentation hardness values were used to evaluate the dispersion of nanoparticle into the U75H25 matrix manufactured using two different methods. Creep, scratch and wear tests were carried out to study the effect of nanoparticle addition. It was found that the addition of a low volume fraction of nanoclay $(0.5$ wt. $\%)$ can significantly increase creep, scratch and wear resistance of the polyethylene nanocomposites. This was attributed to the improvement in the dispersion and exfoliation of nanoclay and also the interaction between the platelets and the $\mathrm{U} 75 \mathrm{H} 25$ matrix. 


\section{References}

[1] Kelly, J.M., Ultra-high molecular weight polyethylene. Journal of Macromolecular Science, Part C: Polymer Reviews, 42(3), pp. 355-371, 2002.

[2] Lucas, A.A., Ambrósio, J.D., Otaguro, H., Casta, L.C. and Agnelli, J.A.M., Abrasive wear of HDPE/UHMWPE blends. Wear, 270, pp. 576-583, 2011.

[3] Lim, K.L.K., Mohd-Ishak, Z.A., Ishiaku, U.S., Fuad, A.M.Y., Yusof, A.H., Czigany, T., Pukanszky, B. and Ogunniyi, D.S., High-density polyethylene/ultrahigh-molecular-weight polyethylene blend. I. The processing, thermal, and mechanical properties. Journal of Applied Polymer Science 97, pp. 413-425, 2005.

[4] Chen, Y., Qi, Y., Tai, Z., Yan, X., Zhu, F. and Xue, Q., Preparation, mechanical properties and biocompatibility of graphene oxide/ultrahigh molecular weight polyethylene composites. European Polymer Journal,48, pp. 1026-1033, 2012.

[5] Ren, P.G., Di, Y.Y., Zhang, Q., Li, L., Pang, H. and Li, Z.M., Composites of Ultrahigh-Molecular-Weight Polyethylene with Graphene Sheets and/or MWCNTs with Segregated Network Structure: Preparation and Properties Macromolecular Materials and Engineering, 297, pp. 437-443, 2012.

[6] Sui, G., Shong, W.H., Ren, X., Qang, X.Q. and Yang, X.P., Structure, mechanical properties and friction behavior of UHMWPE/HDPE/carbon nanofibers. Materials Chemistry and Physics, 115, pp. 404-412, 2009.

[7] Kontou, E. and Niaounakis, Thermo-mechanical properties of LLDPE/SiO nanocomposites. Polymer, 47, pp. 1267-1280, 2006.

[8] Zoo, Y.S., An, J.W., Lim, D.P. and Lim, D.S., Effect of Carbon Nanotube Addition on Tribological Behavior of UHMWPE Tribology Letters, 16(4), pp. 305-309, 2004.

[9] Zhenhua, L. and Yunxuan, L., Mechanical and Tribological Behaviour of UHMWPE/HDPE Blends Reinforced with SBS. Polymer-Plastic Tech. \& Eng., 51, pp. 750-753, 2012.

[10] Xue, Y., Wu, W., Jacobs, O. and Schädel, Tribological behaviour of UHMWPE/HDPE blends reinforced with multi-wall carbon nanotubes Polymer Testing, 25, pp. 221-229, 2006.

[11] Stoeffler, K., Lafleur, P.G., Florence, P.S., Bureau, M.N. and Denault, Micro-mechanisms of deformation in polyethylene/clay micro- and nanocomposites J. Composites: part A, 42, pp. 916-927, 2011.

[12] Fischer-Cripps, A.C., Nanoindentation, Springer-Verlag, NY, 2002.

[13] Aldousiri, B., Dhakal, H.N., Onuh, S., Zhang, Z.Y. and Bennett, N., Nanoindentation behaviour of layered silicate filled spent polyamide-12 nanocomposites. Polymer Testing, 30, pp. 688-692, 2011.

[14] Yusoh, K., Jin, J. and Song, M, Subsurface mechanical properties of polyurethane/organoclay nanocomposite thin films studied by nanoindentation. Progress in Organic Coatings, 67, pp. 220-224, 2010. 
[15] Wang, Z.Z., Gua, P. and Zhang, Z., Indentation and scratch behavior of nano- $\mathrm{SiO}_{2} /$ polycarbonate composite coating at the micro/nano-scale. Wear, 269, pp. 21-25, 2010.

[16] Sabic, Saudi Arabia, http://www.sabic.com

[17] ExxonMobil Chemical Europe, Belgium, http://www.exxonmobil chemical.com

[18] Elementis Specialties, USA, http://www.elementis-specialties.com.

[19] Nanocyl, Belgium, http://www.nanocyl.com

[20] Sigma-Aldrich, UK, www.sigmaaldrich.com

[21] Oliver, W. C. and Pharr, G. M., An improved technique for determining hardness and elastic modulus using load and displacement sensing indentation experiments. J. Mater. Res, 7:6, pp. 1564-1583, 1992. 